\title{
Intestinal permeability in patients with yersinia triggered reactive arthritis
}

\author{
Riitta Lahesmaa-Rantala, Karl-Eric Magnusson, Kaisa Granfors, Rauli Leino, \\ Tommy Sundqvist, Auli Toivanen
}

\begin{abstract}
The passive intestinal permeability of patients with yersinia triggered reactive arthritis was studied using different sized polyethylene glycols (PEGs) contained in a mixture of PEG 400 and PEG 1000. The investigation was carried out at least one year after the onset of yersinia infection, and patients had neither acute gastrointestinal nor joint symptoms. The control groups included patients with uncomplicated yersiniosis as well as healthy subjects who were either HLA-B27 positive or negative. An altered intestinal barrier function to PEG molecules was detected in patients with a history of yersinia infection compared with healthy controls. No significant differences in the permeability were found between patients with or without reactive arthritis, nor was there any association of increased permeability with HLA-B27. The passive permeability of the intestinal mucosa to the larger molecules was increased for an unexpectedly long time after the acute yersinia infection, probably contributing to the perpetuation of joint symptoms in subjects susceptible to a chronic joint disease.
\end{abstract}

A variety of intestinal disorders are linked with HLA-B27 associated arthropathies, including enteric arthritides triggered by yersinia, salmonella, shigella, and campylobacter as well as joint diseases following chronic inflammatory bowel diseases, ulcerative colitis, and Crohn's disease. ${ }^{12}$ The association between klebsiella and ankylosing spondylitis indicates the role of the gut also in the pathogenesis of this rheumatic disease. ${ }^{34}$ Both microscopic and macroscopic gut lesions have been shown in enteric and idiopathic reactive arthritides as well as in ankylosing spondylitis, indicating subclinical bowel inflammation. 56 It seems that disturbance of intestinal barrier function by infection may be an important factor in the development of joint symptoms.

Impaired ability of the gut mucosa to exclude different sized test molecules has earlier been reported in inflammatory bowel diseases and ankylosing spondylitis. ${ }^{7-9}$ Serrander $e t$ al found increased intestinal permeability in four patients with yersinia triggered reactive arthritis shortly after the onset of the infection ${ }^{10}$; patients with uncomplicated yersiniosis were not studied. In their patients permeability changes induced by infection returned to normal within about two months.

Obviously, acute gastrointestinal infection affects gut permeability. Genetic predisposition-for example, association with HLAB27, might also have a role, however, predisposing either to chronic infection or to immunopathological events in the gut. Furthermore, the existence of a genetically abnormal gut mucosa remains a possibility.

Investigators are actively pursuing the question of whether or not the gut in patients with rheumatoid arthritis is intrinsically abnormal. ${ }^{11}$ So far, no clear supporting evidence exists. Reactive arthritis in which the triggering microbe is known offers a unique opportunity to distinguish between the role of infection and that of genetic predisposition in intestinal permeability. A study of reactive arthritis has a distinct advantage, compared with ankylosing spondylitis or rheumatoid arthritis, for example, in that controls who have had gastrointestinal disease without postinfection complication are available.

In our study the relative importance of HLAB27 or a previous yersinia infection, or both, for intestinal permeability was studied. To avoid the influence of acute intestinal infection or drug treatment we studied a group of patients all symptomless at the time of investigation and having earlier had yersinia infection either uncomplicated or followed by reactive arthritis.

\section{Patients and methods}

PATIENTS AND CONTROLS

Sixteen patients with a history of infection caused by Yersinia enterocolitica 0:3 were studied. The diagnosis of yersinia infection was based on significantly raised yersinia specific antibodies, measured by enzyme linked immunosorbent assay (ELISA), ${ }^{12}$ and a typical clinical picture. $Y$ enterocolitica was isolated from the stools of nine patients. Eight of these patients (six men, two women; aged 40 (SD 12) years) had developed reactive arthritis after yersiniosis and were all tissue typed as HLAB27. The other eight patients (six men, two women; aged 40 (11) years) had recovered from their gastrointestinal infection with no postinfection complications and were negative for HLA-B27 tissue antigen. The investigation was carried out at least one year after the onset of the patients' infection, and all patients were clinically recovered from all gastrointestinal and joint symptoms. Consequently, test subjects were receiving no drugs. The controls included 18 healthy volunteers, 10 of whom were HLA-B27 positive (one man, nine women; aged 35 (16) years) and eight HLA-B27 negative (one man, seven women; aged 31 (7) years). 
POLYETHYLENE GLYCOL ABSORPTION TEST After an overnight fast test subjects were given a $200 \mathrm{ml}$ liquid meal orally (oral rehydration fluid; Semper, Sweden) containing about 20 different sized polyethylene glycols (PEGs) in the mixture with $0.1 \mathrm{~g}$ of PEG 400 and $2.5 \mathrm{~g}$ of PEG 1000 (Macrogolum 400/1000; Apoteksbolaget, Sweden). Once an hour for the next six hours test subjects drank one glass of water during the urine collection period. Thereafter, the total urine volume was measured, and samples of urine were frozen at $-20^{\circ} \mathrm{C}$ until analysis.

\section{ANALYSIS OF PEG}

The procedures used for extraction and analysis of the recovery of PEGs have been described elsewhere. ${ }^{1314}$ Briefly, PEG was extracted from the urine samples with an Amberlite MB-3 anionic and cationic exchange resin. Thereafter, the PEGs of different molecular weight were separated from each other by high performance liquid chromatography. Peaks (size range 238-1250 daltons in PEG 400-PEG $1000 \mathrm{mix}$ ture) were detected by a refractive index meter (HSRI 931; Tecator AB, Sweden).

\section{DESCRIPTION OF THE INTESTINAL BARRIER}

In addition to determining the percentage recovery of different sized PEGs in the urine during the six hour collection period, we further characterised the intestinal barrier by determining the maximum PEG recovery (Rmax; the highest observed percentage of PEG recovery in each subject) and the break point (representing the PEG size at which $50 \%$ of intestinal filtering of PEGs had occurred). The coefficient of variation between two independent measurements of intestinal permeability in healthy subjects has previously been shown to be more than $95 \%$ dependent on the size of the PEG. ${ }^{15}$ Statistical analysis of these variables was by Student's $t$ test. Further evaluation of the differences between the groups of patients was also made by comparing the sum of ranks for each patient, based on the relative urinary excretion of all sizes of PEG molecules or those $>370$ daltons.

\section{Results}

RECOVERY OF PEG MOLECULES IN SIX HOUR URINE SAMPLES

A slightly increased intestinal permeability was noted in HLA-B27 positive patients who had

Intestinal permeability characteristics in patients with a previous infection with Yersinia enterocolitica. Mean (SEM) is given for each variable

\begin{tabular}{|c|c|c|c|c|}
\hline Group & $\begin{array}{l}\text { Number of } \\
\text { patients }\end{array}$ & $\begin{array}{l}\text { Break point } \\
\text { (daltons) }\end{array}$ & $\begin{array}{l}\text { Maximal } \\
\text { recovery } \\
(R \max ; \%)\end{array}$ & $\begin{array}{l}\text { PEGt size } \\
\text { at Rmax } \\
\text { (daltons) }\end{array}$ \\
\hline $\begin{array}{l}H L A-B 27 \text { positive } \\
\text { Reactive arthritis } \\
\text { Healthy controls }\end{array}$ & $\begin{array}{r}8 \\
10\end{array}$ & $\begin{array}{l}714(27) \\
704(14)\end{array}$ & $\begin{array}{l}40 \cdot 3(7 \cdot 1) \\
33 \cdot 2(2 \cdot 2)\end{array}$ & $\begin{array}{l}546(14)^{* *} \\
498(12)\end{array}$ \\
\hline $\begin{array}{l}\text { HLA-B27 negative } \\
\text { Uncomplicated yersiniosis } \\
\text { Healthy controls }\end{array}$ & $\begin{array}{l}8 \\
8\end{array}$ & $\begin{array}{l}718(19) \\
707(15)\end{array}$ & $\begin{array}{l}40 \cdot 2(2 \cdot 3) \\
37 \cdot 4(4 \cdot 0)\end{array}$ & $\begin{array}{l}563(17)^{*} \\
519(12)\end{array}$ \\
\hline
\end{tabular}

had yersinia triggered reactive arthritis than in the HLA-B27 positive healthy controls (fig 1A). This was seen for PEG molecules of all different sizes, but the rank sum test disclosed no significant differences. Similarly, there were no differences between patients with reactive arthritis and those with uncomplicated yersiniosis (fig 1B). Thus the permeability was not dependent on the development of arthritis or on the presence of HLA-B27.

\section{INTESTINAL FILTERING}

Further analysis showed that permeability was increased most with respect to the larger test molecules. The table shows the characteristics describing the ability of the gut to exclude molecules owing to size. Break point values, describing the molecular weight at which $50 \%$ of the intestinal filtering occurs, tended to be higher in patients who had had yersinia infection than in healthy controls; the maximal recovery $(R \max ; \%)$ showed the same tendency (table). The size of the PEG at the point of maximal recovery was significantly greater
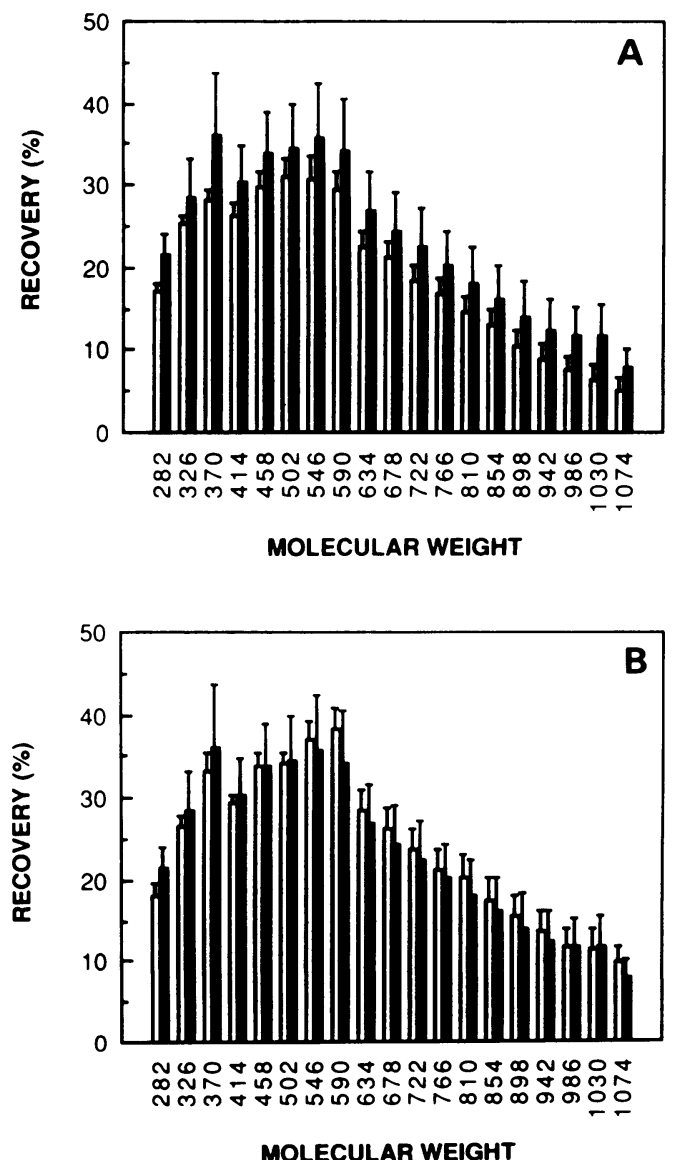

Figure 1 Gastrointestinal permeability of patients with a history of yersinia infection and of normal controls as history of yersinia infection and of normal controls as polyethylene glycols (PEGs) in the mixture of PEG 400 and $P E G 1000$. (A) Comparison of the recovery of PEGs in patients who had had yersinia triggered reactive arthritis ( $n=8$; filled columns) with that in healthy HLA-B27 positive normal controls ( $n=10$; open columns).

(B) Recovery of PEGs in HLA-B27 positive patients who had had yersinia triggered reactive arthritis ( $n=8$; filled columns) and in HLA-B27 negative patients with a history of uncomplicated yersiniosis (open columns; $n=8$ ). Mean (SEM) is given for each PEG size. 
HLA B27+

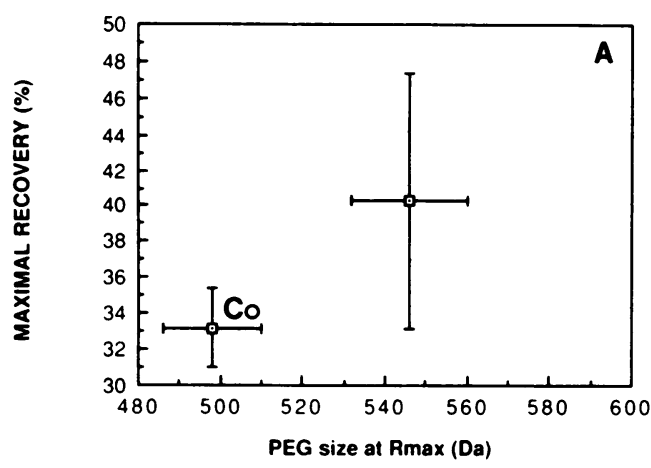

HLA B27-

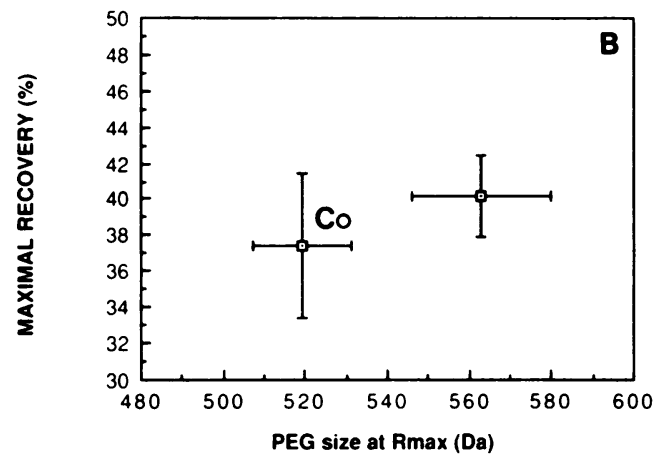

Figure 2 Group characteristics for the intestinal filtering of different sized polyethylene glycols, as described by the maximal recovery ( $R \max ; \%)$ versus $P E G$ size (daltons) at $R \max$. Mean $(S E M)$ is given for each variable. $(A)$ Intestinal filtering characteristics in $H L A-B 27$ positive patients with yersinia triggered reactive arthritis and in $H L A-B 27$ positive healthy controls $(C o)$. $(B)$ The same variables in $H L A-B 27$ negative subjects with uncomplicated yersiniosis compared with HLA-B27 negative healthy controls $(\mathrm{Co})$.

(Student's $t$ test) in patients with earlier yersinia infection than in healthy controls: mean (SEM) 546 (14) $v 498$ (12) in HLA-B27 positive subjects $(\mathrm{p}<0.01)$ and $563(17) v 519(12)$ in HLA-B27 negative subjects $(\mathrm{p}<0.025)$. The effect of a previous infection was even more apparent when $R \max (\%)$ was plotted against the PEG size at $R \max$ (figs $2 \mathrm{~A}$ and $\mathrm{B}$ ). The difference between the control groups of HLAB27 positive and negative subjects was still small and not significant (figs $2 \mathrm{~A}$ and $\mathrm{B}$ ).

\section{Discussion}

In this study intestinal permeability tended to be greater in patients who had had yersinia infection than in controls who had not had yersiniosis (fig 1A). Surprisingly, the influence of infection, which was noted during the acute phase of infection and seemingly returned to normal after less than two months, ${ }^{10}$ could be still seen over one year after the onset of the disease. No greater increase in intestinal permeability was found, however, in patients who developed yersinia triggered reactive arthritis than in those with uncomplicated yersiniosis; nor was it linked to HLA-B27.

It is of interest to consider the reason(s) for the prolonged increased intestinal permeability of these patients compared with controls. Nonsteroidal anti-inflammatory drugs, which are known to induce mucosal changes and increase intestinal permeability, ${ }^{1617}$ cannot be the cause as none of the patients was receiving them. Whether this functional change in intestinal barrier is due to some chronic structural changes induced by acute infection, or whether there is a chronic latent inflammation developing after apparent recovery of the mucosal barrier ${ }^{10}$ remains an open question. Both macroscopic and microscopic changes have been found in patients with reactive arthritis ${ }^{56}$ as well as in those with acute gastroenteritis (LeirisaloRepo, personal communication). There are, however, no follow up studies comparing patients with enteroarthritis and uncomplicated gastrointestinal infection which would show how long after the onset of infection these lesions can be seen.

At least two possible reasons might explain the chronic latent inflammation in patientsnamely, persistence of yersinia antigens or prolonged changes in intestinal flora. Persistence of yersinia antigens in the host is suggested by the persistence and maturation of IgA responses in patients with yersinia triggered reactive arthritis ${ }^{1218} 19$ and indicated also by the prolonged occurrence of immune complexes containing yersinia antigens. ${ }^{20}$ Recently, yersinia antigens have been found in gut biopsy specimens of patients with chronic infections. ${ }^{21}$ In some of these patients such antigen persistence might affect intestinal permeability. As for the second possibility, it is not yet known what kind of changes in the intestinal flora are induced by acute gastroenteritis. In rheumatoid arthritis the changes reported in intestinal microbial flora ${ }^{22}$ may affect gut permeability through inflammation. Combined disturbances in intestinal permeability and microbial flora may increase the antigenic load of gut associated lymphoid tissue and circulation, with potentially harmful consequences in susceptible subjects.

In normal uninfected subjects mainly small molecules are permitted through the mucosal barrier. In contrast, larger molecules seemed able to pass the intestinal barrier in patients with history of yersiniosis. Increased passage of molecules through the intestinal barrier was noted particularly for the larger molecules. A similar permeability profile has also been found in patients with Crohn's disease, ${ }^{7}$ where with increasing frequency larger PEG molecules are allowed to pass the gut barrier. ${ }^{9}$ This might be explained by the similar localisation of gut inflammation in the two diseases.

Although an altered intestinal barrier function was shown in the patients studied, no joint symptoms were evident at the time of investigation. The present patient group did not include those with chronic joint symptoms, which are seen in about $10-20 \%$ of patients with yersinia reactive arthritis. ${ }^{24}$ Furthermore, about $50 \%$ had some minor problems, such as back pain. ${ }^{24}$ In experimental animal models the perpetuation of arthritis, once triggered, can be achieved by injecting a variety of antigens into genetically susceptible animals. ${ }^{25}$ Possibly, therefore, by allowing increased access to both microbial and dietary antigens, increased gut permeability to large molecules might have a 
crucial role in the chronic aspect of arthritis. The essential question is whether or not gut is intrinsically abnormal in rheumatic diseases. ${ }^{11}$ Results presented herein suggest that this is not the case; at least in yersinia triggered reactive arthritis, an infection, rather than a predisposing intrinsic factor (HLA-B27 status), seems to have led to impaired intestinal barrier.

We thank Mrs Anita Sjö, and Ms Sari Tasa for skilful technical help, Dr Erik K Leander for statistical advice, and Dr Jeri L Hill for critical review of the manuscript. This study was supported by the Sigrid Jusélius Foundation, the Yriö Jahnsson Foundation, by the Sigrid Jusélius Foundation, the Yriö Jahnsson Foundation, King Gustaf Vth 80 -Year Foundation, Professor Nanna Svartz
Foundation, and the Swedish Medical Research Council (project No 6251).

1 Lahesmaa-Rantala $\mathrm{R}$, Toivanen A. Clinical spectrum of reactive arthritis. In: Toivanen $A$, Toivanen $P$, eds Reactive arthritis. Boca Raton: CRC Press, 1988: 1-13.

2 Brewerton D A. Causes of arthritis. Lancet 1988; ii: 1063-6.

3 Ebringer $R$ W, Cawdell D R, Cowling P, Ebringer A. Sequential studies in ankylosing spondylitis. Association of Klebsiella pneumoniae with active disease. Ann Rheum Dis 1978; 37: 146-51.

4 Calin A. Pathogenesis of ankylosing spondylitis: the state of the art. Br $\mathcal{Y}$ Rheumatol 1988; 27 (suppl 2): 106-9.

5 Mielants H, Veys E M, Cuvelier C, De Vos M, Botelberghe L. HLA-B27 related arthritis and bowel inflammation. Part 2. Ileocolonoscopy and bowel histology in patients with HLA-B27 related arthritis. $\mathcal{F}$ R heumatol 1985; 12: 294-8.

6 Cuvelier C, Barbatis C, Mielants H, De Vos M, Roels H Veys E. Histopathology of intestinal inflammation related to reactive arthritis. Gut 1987; 28: 394-401.

7 Magnusson K-E, Sundqvist T, Sjödahl R, Tagesson C. Altered intestinal permeability to low-molecular-weigh polyethyleneglycols (PEG 400) in patients with Crohn's disease. Acta Chir Scand 1983; 149: 323-7.

8 Smith M D, Gibson R A, Brooks P M. Abnormal bowel permeability in ankylosing spondylitis and rheumatoid permeability in ankylosing spondylitis

9 Olaison G, Leandersson P, Sjödahl R, Tagesson C. Intestinal permeability to polyethyleneglycol 600 in Crohn's disease. Peroperative determination in a defined segment of the small intestine. Gut 1988; 29: 196-9.

10 Serrander R, Magnusson K-E, Kihlström E, Sundqvist T Acute yersinia infections in man increase intestinal permeability for low-molecular weight polyethylene glycols. Scand F Infect Dis 1986; 18: 409-13.

11 Doube A, Collins A J. Is the gut intrinsically abnormal in rheumatoid arthritis? Ann Rheum Dis 1988; 47:617-9.
12 Granfors $K$, Vilianen $M \quad K$, Tiilikainen A, Toivanen A. Persistence of IgM, IgG and IgA class yersinia antibodies in Persistence of IgM, IgG and IgA class yersinia an

13 Fälth-Magnusson $\mathrm{K}$, Kjellman N-I M, Sundqvist $T$, Magnusson K-E. Gastrointestinal permeability in atopic polyethylene glycols (PEG 400 and PEG 1000). Clin Allergy 1985; 15: 565-70.

14 Fälth-Magnusson K, Kjellman N-I M, Odelram H, Sundqvist T, Magnusson K-E. Gastrointestinal permeability in children with cow's milk allergy; effect of milk challenge and sodium cromoglycate as assessed with polyethyleneglycols (PEG 400 and PEG 1000). Clin Allergy 1986; 16: glycols

15 Fälth-Magnusson K, Kjellman N-I M, Magnusson K-E, Sundqvist $T$. Intestinal permeability in healthy and allergic subjects before and after sodium cromoglycate treatment subjects before and atter sodium cromoglycate treatment assessed with different-sized polyethylene glycols

16 Bjarnason I, Williams P, So A, et al. Intestinal permeability and inflammation in rheumatoid arthritis: effects of nonsteroidal anti-inflammatory drugs. Lancet 1984; ii: $1171-4$.

17 Bjarnason I, Williams P, Smethurst P, Peters T J, Levi A J. Effect of non-steroidal anti-inflammatory drugs and prostaglandins on the permeability of the human small intestine. Gut 1986; 27: 1292-7.

18 Lahesmaa-Rantala R, Lehtonen O-P, Granfors K, Toivanen A. Avidity of anti-yersinia antibodies in yersiniosis patients with and without yersinia-triggered reactive arthritis. Arthritis Rheum 1987; 30: 1176-81.

19 Toivanen A, Lahesmaa-Rantala R, Vuento R, Granfors K. Association of persisting $\operatorname{IgA}$ response with yersiniaAssociation of persisting $\lg A$ response with yersinia-
triggered reactive arthritis. A study on 104 patients. Ann triggered reactive arthritis. A
Rheum Dis 1987; 46: 898-901.

20 Lesma-Rantala R, Granfors K, Kekomäki R, Toivanen A Circulating yersinia-specific immune complexes after acute yersinoisis: a follow-up study of patients with and without reactive arthritis. Ann Rheum Dis 1987; 46: 121-6.

21 de Koning J, Heesemann J, Hoogkamp-Korstanje J A A Festen J J M, Houtman PM, van Oijen P L M. Yersinia in intestinal biopsy specimens from patients with seronegative spondyloarthropathy: correlation with specific serum IgA antibodies. F Infect Dis 1989; 159: 109-12.

22 Olhagen B. Intestinal Clostridium perfringens in arthritis and allied conditions. In: Dumonde D C, ed. Infection and immunology in rheumatic diseases. Oxford: Blackwell, 1976: immun 5 .

23 Schinebaum R, Neumann V C, Cooke E M, Wright V. Comparison of faecal flora in patients with rheumatoid Comparison of faecal flora in patients with rheumatoid

24 Leirisalo-Repo M, Suoranta H. Ten-year followup study of patients with yersinia arthritis. Arthritis Rheum 1988; 31 : 533-7

25 van den Broek M F, van den Berg W B, van de Putte L B A, Severijnen A J. Streptococcal cell wall-induced arthritis and flare-up reaction in mice induced by homologous or heterologous cell walls. Am $\mathcal{f}$ Pathol 1988; 133: 139_49. 